\title{
VARIABILIDADE DIÁRIA DA PRECIPITAÇÃO EM REGIÕES DE FLORESTA E PASTAGEM NA AMAZÔNIA
}

\author{
Rafael FERREIRA DA COSTA', João Roberto Pinto FEITOSA ${ }^{1}$, Gilberto \\ FISCH $^{2}$, Solange Silva de SOUZA', Carlos A. NOBRE'
}

RESUMO - As estaçōes automáticas do Projeto ABRACOS instaladas na Amazônia Ocidental fomeceram os dados horários de precipitação em áreas de pastagem e floresta, durante o trimestre mais chuvoso $(\mathrm{j} / \mathrm{f})$ m) no período de 1992 a 1995. A variabilidade diária de precipitação maior que $1 \mathrm{~mm} \mathrm{~h}^{-1}$ mostrou uma frequência relativa de $6,7 \%$ dos casos às 14 horas local (hl) na pastagem e $5,7 \%$ às $16 \mathrm{hl}$ na floresta. $\mathrm{O}$ periodo da tarde (13-18 hl) registra acima de 30\% dos eventos de precipitação em ambos os sítios. Há uma boa regularidade na distribuição horária dos eventos, principalmente na floresta. Para as precipitações maiores que $10 \mathrm{~mm} \mathrm{~h}^{-1}$, existe uma concentração dos casos no final da tarde. Na pastagem $12,3 \%$, e na floresta $11,5 \%$ dos eventos ocorrem às $18 \mathrm{hl}$. O intervalo entre $7-18 \mathrm{hl}$ detérn $64,9 \%$ dos casos na pastagem, e $57,7 \%$ na floresta. Do total de eventos de precipitação, $14 \%$ são maiores que $10 \mathrm{~mm} \mathrm{~h}^{-1}$, tanto na floresta como na pastagem. Comparando-se o total de chuva ocorrido nas áreas de floresta e pastagem, o volume precipitado na floresta é cerca de $28 \%$ em média superior ao da pastagem.

Palavras chaves: Precipitação; variabilidade diária; pastagem; floresta.

Daily Variability of Rainfall in Pasture and Forest Regions in the Amazonia.

ABSTRACT - Measurements of hourly rainfall were made with an automatic weather station in ABRACOS Project sites of pasture and forest in the Amazonia rainforest between 1992-1995 in the rainy season (jan/feb/mar). Daily variability of rainfall higher than $1 \mathrm{~mm} \mathrm{~h}^{-1}$ showed a relative frequency of $6.7 \%$ at 14 local time (LT) on the pasture site, and $5.7 \%$ at 16 LT to the forest. The afternoon period (13$18 \mathrm{LT}$ ) registered above $30 \%$ of rainfall events in the forest and pasture To rainfall higher than $10 \mathrm{~mm} \mathrm{~h}^{-1}$, there is an evening concentration, $12.3 \%$ of events in the pastureland, and $11.5 \%$ on the forest occurred at $18 \mathrm{LT}$, The period between $7-18 \mathrm{LT}$ concentrate $64.9 \%$ of events on the pastureland and $57.7 \%$ on the forest. Of the total rainfall events, $14 \%$ are higher than $10 \mathrm{~mm} \mathrm{~h}^{-1}$, in the both sites. The comparison of the total rainfall measured in sites showed on average values $28 \%$ higher on the forest than pasture.

Key-words: Rainfall; daily variability; pasture; forest.

"As lendárias Amazonas, mulheres guerreiras que no século XVI teriam combatido os conquistadores europeus, deram origem ao nome da vasta regiào equatorial na América do Sul, a qual denomina-se Amazonia. Passados mais de 300 anos, ainda mostra-se uma região desafiadora para os conquistadores."

\section{INTRODUÇÃO}

Com uma área de aproximadamente cinco milhões de quilômetros quadrados, a Amazônia é a maior bacia hidrográfica do mundo. A parte brasileira compreende três milhões, oitocentos e cinquenta mil quilômetros quadrados que representam quarenta e cinco porcento do território nacional. Floresta equatorial de clima quente e úmido, a Amazônia possui características bastante peculiares. A ocorrência de longos e intensos periodos de chuva é um dos fatores que diferem esta região de outras partes do globo.

A precipitaçâo é fundamental para a caracterização climática. Os amazônidas distinguem as estações do ano pelas épocas chuvosas e secas, porém, o período de ocorrência e a intensidade

Centro de Previsão de Tempo e Estudos Climáticos - Instituto Nacional de Pesquisas Espaciais (CPTECINPE), Cachoeira Paulista, CEP 12630-000, SP, Brasil

2 Centro Técnico Aeroespacial (CTA / IAE - ACA), São José dos Campos, CEP 12228-904, SP, Brasil 
destas fases dependem da localização geográfica. Salati et al. (1978), usando balanço hídrico, técnicas isotópicas e métodos aerológicos, notaram que a floresta contribui com $50 \%$ da chuva, e a outra metade seria decorrente da advecção de umidade do Oceano Atlântico. A bacia amazônica é um dos principais centros de atividades convectivas na região tropical do globo (Peagle, 1987). Durante a época chuvosa, grandes nuvens convectivas operam como principais produtores de chuva, e origem dos movimentos de ar, umidade e gases atmosféricos entre o dossel florestal e a média e alta troposfera (Grecco et al., 1990).

Durante o século XIX e o início do século $\mathrm{XX}$, várias foram as tentativas de exploração econômica da floresta amazônica, Porém, na segunda metade do século, a evolução tecnológica permitiu uma nova aventura exploratória na região amazônica. Desta vez foram projetos agropecuários, interligados por colossais estradas de rodagem que rasgaram a floresta virgem em todas as direções. Projetos de rodovias como a Belém-Brasilia (BR010), CuiabáSantarém (BR163), Manaus - Porto Velho (BR319), Manaus - Boa Vista (BR174), Cuiabá - Porto Velho - Rio Branco (BR364) e a megalômana Transamazônica (BR230) cortando longitudinalmente a região, deram origem à ocupação desenfreada da floresta. Os grandes picos destas aventuras amazônicas tiveram seu lugar nas décadas 70 e 80 , quando coincidiram com a explosão das atividades garimpeiras na região.
Toda esta movimentação de massas populacionais migrantes, provocou uma enorme transformação nas caracteristicas fisicas originais da floresta. Extrativismo vegetal associado com a implantação agropecuária e garimpo, foram as atividades antropogênicas responsáveis pela retirada e/ou substituição da floresta primária.A troca da vegetação natural por outro tipo de cobertura vegetal altera as interações água-soloplanta-atmosfera. Estas modificações ocorridas em grande escala podem ter efeitos no clima regional (Nobre et al.; 1991). Utilizando resultados de simulações climáticas para análise do efeito do desmatamento na Amazônia, Fisch et al. (1997), encontraram reduções no saldo de radiação de ondas curtas $(8 \%)$ e total $(3 \%)$, na umidade especifica, na evaporação $(20 \%)$, e na precipitação $(14 \%)$ em nivel sazonal. Simularam também aumentos na velocidade do vento e na temperatura média do ar $\left(0,9^{\circ} \mathrm{C}\right)$, assim como um prolongamento na época seca. Para que fosse possível uma compreensão destas modificações e suas consequências ao meio ambiente e ao clima regional com possíveis implicações globais, foram planejados e postos em prática vários experimentos científicos na Amazônia. Destacam-se os experimentos Arme (Shuttleworth et al. 1984) e Able (Harriss et al. $1988 ; 1990$ ).

Recentemente outro experimento realizado, com grande impacto positivo para as pesquisas na Amazônia, foi o Projeto ABRACOS, acrônimo para Anglo-BRazilian Amazonian Climate Observation Study. 
Desenvolvido entre 1990 e 1995 , este projeto instalou três sitios experimentais na Amazônia, sendo que cada um possui postos de pesquisas em áreas de vegetação primária (floresta) e em locais de atividades agropecuária (pastagem). Segundo Shuttleworth et al. (1991), o projeto ABRACOS foi concebido para operar em duas escalas de tempo. Uma escala hidrológica ou climatológica onde são realizadas mensurações contínuas, para utilização em estudos de longa duração e análises das diferenças entre tipos de vegetação. A outra escala é para observações dos processos fisiológicos vegetais e micrometeorológicos, obtidas durante a efetivação de campanhas intensivas de coleta de dados com duração de semanas.

Este trabalho foi realizado com o objetivo de se analisar a distribuiçâo horária da precipitação, durante a época chuvosa, nas áreas de floresta e pastagem na região sudoeste da Amazônia. Serão analisadas a variabilidade diária da precipitação e as alterações ocorridas, possivelmente devido ao desmatamento.

\section{MATERIAIS E MÉTODOS}

\section{- Descrição dos sítios experimentais.}

O projeto ABRACOS possui três sítios experimentais na Amazônia, a saber: Manaus - AM (central), Marabá - PA (leste), e Ji-paraná - RO (oeste). Cada um é composto por duas áreas distintas, sendo uma com vegetação primária, floresta de grande porte, e outra com vegetação de pastagem. Nas áreas de floresta foram instaladas torres micrometeorológicas com 52 metros de altura, que ultrapassam o topo do dossel vegetal, enquanto as pastagens receberam torres semelhantes, porém com apenas cinco metros de altura. Em todos os pontos de pesquisas foram colocadas estações climatológicas automáticas (ECA) idênticas, tanto na floresta como na pastagem. Uma descrição detalhada dos sítios experimentais e do instrumental utilizado encontra-se em Gash et al. (1996).

Os sitics experimentais foram montados na faixa nordeste do estado, na área de influência dos municípios de Ji-Paraná e Ouro Prêto D'Oeste, representando respectivamente $7,8 \%$ e $3,3 \%$ da população do Estado, que é de 1,22 milhão de habitantes (IBGE, 1996).

A Reserva Biológica do Jarú $\left(10^{\circ}\right.$ $\left.05^{\prime} \mathrm{S}, 61^{\circ} 55^{\prime} \mathrm{W}, 120 \mathrm{~m}\right)$ é uma floresta tropical e está sob responsabilidade do Instituto Brasileiro do Meio AmbienteIBAMA, compreende uma área de aproximadamente 268 mil hectares. Foi instalada uma torre de alumínio, ultrapassando o cume da vegetação que tem altura média de 33 metros, com algumas espécies atingindo até 45 metros, e incidência de Cedrella Odorata, Inga sp, Diocle of bicolorBth., Glycicarpa Ruiz, Strychnos amazonicus (CULF et al. 1995). A pastagem é a Fazenda Nossa Senhora de Aparecida $\left(10^{\circ} 45^{\prime} \mathrm{S}, 62^{\circ} 22^{\prime} \mathrm{W}, 220 \mathrm{~m}\right)$ no município de Ouro Prêto D'Oeste. Estabelecida no início da década de oitenta, possui vegetação tipo Brachiaria Brizantha além de pequenas palmeiras dispersas (McWilliam et al. 1996).

Para a coleta de informações de precipitaçào, em ambos os sitios foram instalados pluviômetros do tipo báscula com resolução de 0,2 mm (Didcot Instru- 
ments Company, Abingdom, UK) com a gravação automática em intervalos de cinco minutos e integração horária em um sistema de aquisição de dados (Campbell Scientific, Shepshed, UK).

\section{- Climatologia de Ouro Prêto D'Oeste.}

Devido a sua localização geográfica em relação aos pontos de coletas, a cidade de Ouro Prêto D'Oeste serve como referência climatológica para a região estudada (Fig. 1).

A climatologia da região está sendo determinada a partir de dados coletados pela Estação Climatológica Experimental de Ouro Prêto D'Oeste $\left(10^{\circ} 44^{\prime} 30^{\prime \prime} \mathrm{S}, 62^{\circ} 12^{\prime} 30^{\prime \prime} \mathrm{W}\right)$ sob responsabilidade da Comissão Executiva do Plano da Lavoura Cacaueira CEPLAC. A série de informações disponivel é de 1982 a 1996 e o instrumental é de uma estação convencional (Scerne et al. 1996).

Para a determinação da precipitação é utilizado um pluviômetro tipo Ville de Paris com superfície de captação de $400 \mathrm{~cm}^{2}$ a uma altura de 1,5 metro do solo. A precipitaçâo diária foi obtida

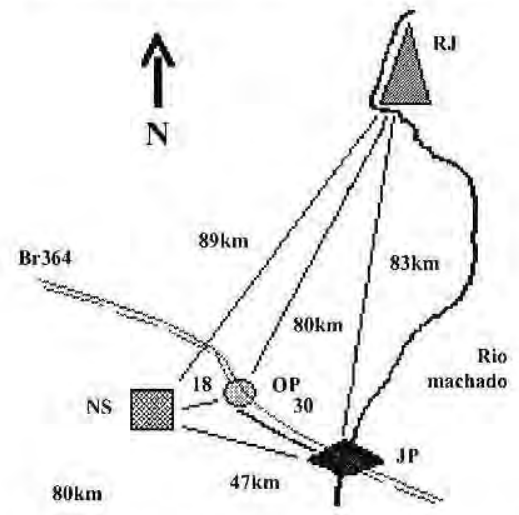

pela soma das observações das 18:00 e 24:00 horas GMT do dia anterior, mais às 12:00h GMT do dia do registro.

\section{- Variabilidade Diária de Precipitação.}

Para a definição do horário com maior ocorrência de eventos de precipitação nas áreas de floresta e de pastagem, foram utilizadas as informações horárias das estações climatológicas automáticas.

O periodo selecionado foi o trimestre mais chuvoso em volume médio diário precipitado, ou seja: janeiro, fevereiro e março $(\mathrm{j} / \mathrm{f} / \mathrm{m})$, para os anos de 1992 a 1995. A Tabela 1 mostra o total de dias e o porcentual para o trimestre chuvoso dos dados utilizados no estudo da variabilidade diária de precipitação.

Somente foram consideradas as precipitações horárias maiores que $1 \mathrm{~mm}$, sendo realizada a contagem do número de eventos de precipitação. A seguir, foi calculada a frequência relativa de precipitação aplicando a relação entre o número de casos de

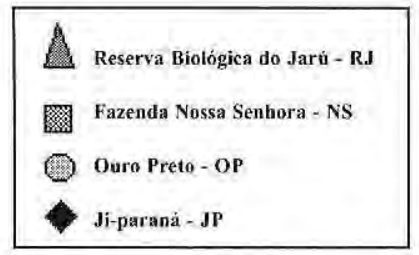

Figura 1, Localização dos Sítios Experimentais de Floresta ( RJ ) e Pastagem (NS). 
Tabela 1. Estatistica dos dias com dados úteis de precipitação durante o trimestre chuvoso (jan/fev/mar) para os sitios de floresta e pastagem em Rondônia (1992 - 1995).

\begin{tabular}{lcccccccccc}
\hline \multicolumn{1}{c}{ Floresta } \\
\hline Ano & 1992 & 1993 & 1994 & 1995 & total & 1992 & 1993 & 1994 & 1995 & total \\
dias & 71 & 86 & 74 & 90 & 321 & 91 & 88 & 74 & 64 & 317 \\
$(\%)$ & 78,0 & 95,6 & 82,2 & 100,0 & 88,9 & 100,0 & 97,8 & 82,2 & 71,1 & 87,8 \\
\hline
\end{tabular}

precipitação da hora e o número total de casos nas 24 horas do dia (SPIEGEL, 1972).

$$
F_{r}=\frac{n_{i}}{N} \times 100
$$

onde: $\mathbf{F}_{r}$ é a frequência relativa de precipitação, $\mathbf{n}_{\mathbf{i}}$ é o número de casos ocorridos em determinada hora e $\mathbf{N}$ é o número total de casos ocorridos nas 24 horas do dia. Estes procedimentos foram realizados para chuvas horárias superiores a $1 \mathrm{~mm}$ e $10 \mathrm{~mm}$. Na sequência, as informações foram integradas em intervalos de 6 horas, nos períodos de $1-6,7-12,13-18$, e 19-24 horas local ( hl ).

\section{- Comparação da precipitação entre} os sítios de floresta e pastagem.

Para determinação da área em que ocorre o maior volume de precipitação entre floresta e pastagem, foram utilizados dados horários das ECAs para o trimestre $\mathrm{j} / \mathrm{f} / \mathrm{m}$ no período de 1992 a 1995. Do universo disponivel de informações, foram selecionados apenas os dias em que haviam dados simultaneamente na floresta e na pastagem (Tab. 2), eliminando assim aquelas informações de apenas um dos sítios, evitando tendenciosidades nos resultados obtidos. Foram analisados 291 dias com informações em ambos os sítios,

Tabela 2. Dias com registros simultâneos dos dados de precipitação para áreas de floresta e pastagem. Periodo: Jan/Fev/Mar/ 1992 a 1995.

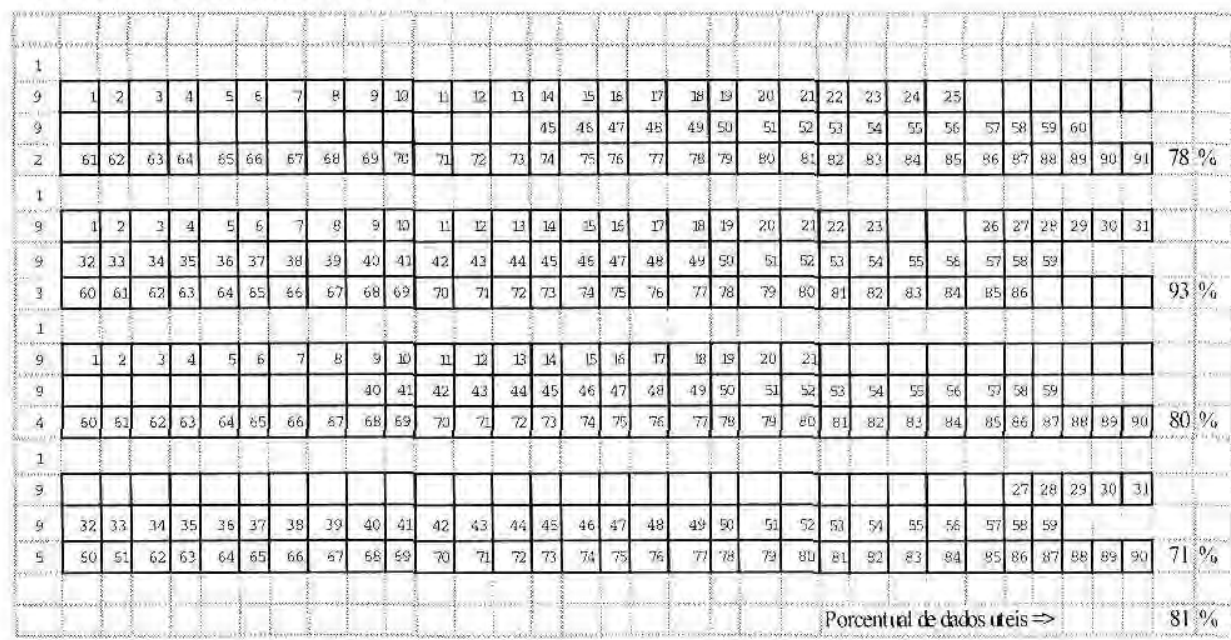

Obs.: Estâo incluidos os dias con registro ZERO de precipitação, sendo eliminados (espaços em branco) apenas os dias en que há medida em somente em I dos sitios experimentais. 
representando $81 \%$ dos dados possíveis.

\section{RESULTADOS E DISCUSSÃO}

\section{- Climatologia de Ouro Prêto D'Oeste com distribuição Mensal} da Precipitação.

Desde que a precipitação é um fator imprescindível na caracterização climática de uma região, a série de 15 anos de dados, disponivel para a Estação de Ouro Prêto D'Oeste foi analisada detalhadamente. Na variação média mensal nota-se um ciclo sazonal bem definido. $\mathrm{O}$ semestre compreendido de novembro a abril registra índices pluviométricos acima de $220 \mathrm{~mm}$ mês ${ }^{-1}$, sendo no mês de janeiro o maior total mensal com $293,8 \mathrm{~mm}$. O período seco abrange os meses de junho a agosto, sendo que o menor registro é no mês de julho com apenas 7,2 $\mathrm{mm}$ precipitados. Fisch et al. (1996) descrevem que os mecanismos de chuva na Amazônia podem ser provocados por convecção local, penetração de cumulunimbus, circulação fluvial de mesoescala ou convecção organizada por entrada de frente fria da região sudeste do Brasil. No caso especifico de Ji-Paraná, a precipitação é predominantemente devido à convecção local, sendo que a distribuição sazonal é decorrente da migração sudeste/noroeste do núcleo de convergência de umidade nos baixos niveis e divergência (Alta da Bolivia) nos altos niveis, conforme mostrado por Horel et al. (1989) e Figueroa \& Nobre (1990).

Os valores totais de precipitação para o periodo disponível indicam o ano de 1990 como o de menor volume com $1693,7 \mathrm{~mm}$, ficando $284 \mathrm{~mm}(14,4 \%)$ abaixo da média anual de $1977,7 \mathrm{~mm}$. No ano de 1986 foi registrado o maior volume de precipitação com um total de $2339,2 \mathrm{~mm}$, ou seja, $361,5 \mathrm{~mm}(18,3 \%)$ superior à média anual. Em valores mensais absolutos, há precipitações próximas aos $500 \mathrm{~mm}(496,4 \mathrm{~mm}$ para março de 1986) e nunca inferiores a 100 $\mathrm{mm}$ para o semestre chuvoso que vai de novembro a abril (Tab. 3 ).

Tabela 3 - Quadro Estatistico da Precipitação para Ouro Prêto D'Oeste-RO(10 $44^{\prime} 30^{\prime \prime} \mathrm{S}, 62^{\circ} 12^{\prime} 30^{\prime \prime}$ W). Periodo: 1982 a 1996.

\begin{tabular}{|c|c|c|c|c|c|c|c|c|c|c|c|c|}
\hline & JAN & FEV & MAR & ABR & MAI & JUN & JUL & AGO & SET & OUT & NOV & DEZ \\
\hline $\mathrm{N}^{\ell}$ de dias com precipitaçăo & 21 & 18 & 19 & 15 & 7 & 2 & 1 & 3 & 6 & 12 & 16 & 19 \\
\hline Máximo absoluto (mm) & 410,2 & 390,9 & 496,4 & 435,7 & 178,8 & 83,8 & 44,8 & 117,8 & 243,5 & 259,5 & 369 & 386,4 \\
\hline Minimo absoluto (mm) & 184,4 & 142,6 & 127,1 & 103 & 3,4 & 0 & 0 & 0 & 5,2 & 84,2 & 115,8 & 176,2 \\
\hline Mèdia mensal (mm) & 293,8 & 272,2 & 286,8 & 223,6 & 76,8 & 19,6 & 7,2 & 32,9 & 95,8 & 153,1 & 237,5 & 278,5 \\
\hline Média diária $(\mathrm{mm})$ & 9,5 & 9,7 & 9,3 & 7,5 & 2,5 & 0,7 & 0,2 & 1,1 & 3,2 & 4,9 & 7,9 & 9,0 \\
\hline$(\%)$ da média anual & 14,9 & 13,8 & 14,5 & 11,3 & 3,9 & 1,0 & 0,4 & 1.7 & 4,8 & 7,7 & 12,0 & 14,1 \\
\hline Média diária (ano) (mm) & \multicolumn{2}{|l|}{5.4} & \multicolumn{3}{|c|}{ Média diária-(j/f/m) (mm) } & 9,5 & \multicolumn{5}{|c|}{ Média diária-(j/j/a) (mm) } & 0,7 \\
\hline Média mensal (ano) (mm) & 164,8 & \multicolumn{4}{|c|}{ Média mensal-(j/f/m) (mm) } & 284,3 & \multicolumn{5}{|c|}{ Média mensal-(j///a) (mm) } & 19,9 \\
\hline \multicolumn{4}{|c|}{ Acumulado para trimestre chuvoso $(\mathrm{j} / \mathrm{f} / \mathrm{m})(\mathrm{mm})$} & 852,8 & \multicolumn{7}{|c|}{ Acumulado para trimestre seco $(\mathrm{j} / \mathrm{j} / \mathrm{a})(\mathrm{mm})$} & 59.7 \\
\hline \multicolumn{4}{|c|}{ (\%) da média anual para trimestre chuvoso (j///m) } & 43,1 & \multicolumn{5}{|c|}{$(\%)$ da média anual para trimestre } & seco & $(j / \mathrm{j} / \mathrm{a})$ & 3,0 \\
\hline Média anual (mm) & 1977,7 & & & & & & & & & & & \\
\hline
\end{tabular}


A média diária mais elevada é registrada no mês de fevereiro com $9,7 \mathrm{~mm} \mathrm{dia}^{-1}$, e a mais baixa em julho com apenas $0,2 \mathrm{~mm} \mathrm{dia}^{-1}$. Para o ano todo, a média é de $5,4 \mathrm{~mm} \mathrm{dia}^{-1}$, sendo no trimestre chuvoso de $9,5 \mathrm{~mm} \mathrm{dia}^{-1}$, e no seco $0,7 \mathrm{~mm} \mathrm{dia}^{-1}$. A média mensal no período é de $164,8 \mathrm{~mm}$, onde janeiro registra a mais elevada com $293,8 \mathrm{~mm}(14,9 \%)$ e julho a menor com apenas $7,2 \mathrm{~mm}(0,4 \%)$. O trimestre chuvoso apresenta a média de $284,3 \mathrm{~mm}$, a precipitação média acumulada é de $852,8 \mathrm{~mm}$ que representam $43,1 \%$ da ocorrência anual, enquanto que para o trimestre seco o acumulado é de $59,7 \mathrm{~mm}$ representando $3 \%$ da média anual de $1977,7 \mathrm{~mm}$. O número de dias com ocorrência de precipitação varia de acordo com a sazonalidade do período (Fig. 2): em média vai de 21 dias em janeiro à apenas 1 dia em julho, $\mathrm{O}$ trimestre chuyoso tem em média 19 dias com chuva e acumula um total médio de 58 dias com precipitação ( 2 . em cada 3 dias), representando $41,7 \%$ do total médio anual de 139 dias.

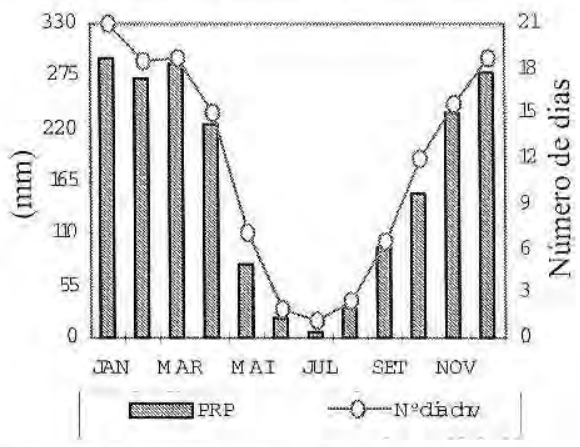

Figura 2. Média mensal da precipitação e do número de dias com precipitação $\mathrm{em}$ Ouro Prêto D'Oeste Rondônia. Periodo: 1982 a 1996. Fonte: CEPLAC.

\section{- Variabilidade Diária de Precipitação.}

A Variabilidade Diária da frequência relativa de precipitação maior que $1 \mathrm{~mm}$ $h^{-1}$ é mostrada na Figura 3. Na área de pastagem (a) observa-se uma distribuição com pouca diferença entre os horários, sendo que a maior frequência de ocorrência é às $14 \mathrm{hl}$ com $6,7 \%$ dos casos, e a menor às $11 \mathrm{hl}$ com 2,2\%. A hora de menor frequência representa cerca de $1 / 3$ do horário de maior frequência. Para a floresta (b) a distribuição mostra-se mais regular que na pastagem. Às $16 \mathrm{hl}$ ocorre a maior frequência de precipitação $(5,7 \%)$, enquanto o menor indice $(2,9 \%)$ é registrado às 10,11 e $23 \mathrm{hl}$. Os horários de menor frequência têm valores que são quase a metade dos registrados na hora de máxima ocorrência. PAIVA (1996), analisando um curto período (nov. 1991 a fev. 1992 na floresta, e fev. a abr. de 1992 na pastagem) encontrou maiores porcentuais à tarde, com picos às $14 \mathrm{e} 18 \mathrm{hl}$ na floresta $\mathrm{e}$ às $18 \mathrm{hl}$ na pastagem.

Para as precipitações maiores que 1 $\mathrm{mm} \mathrm{h}^{-1}$ as ocorrências se intensificam a partir das $13 \mathrm{hl}$, indo até às $16 \mathrm{hl}$ na pastagem, enquanto que na floresta isto ocorre às $14 \mathrm{hl}$ estendendo-se até $18 \mathrm{hl}$. Isto, provavelmente em decorrência de um aquecimento mais rápido da superfície com pastagem, facilitando o desenvolvimento da nebulosidade que atinge a maturação em um espaço de tempo menor, propiciando assim, a ocorrência de precipitação logo no início da tarde e provocando também uma diminuição mais rápida no horário de maior frequência (às $16 \mathrm{hl}$ ) que na floresta (às $18 \mathrm{hl}$ ). 

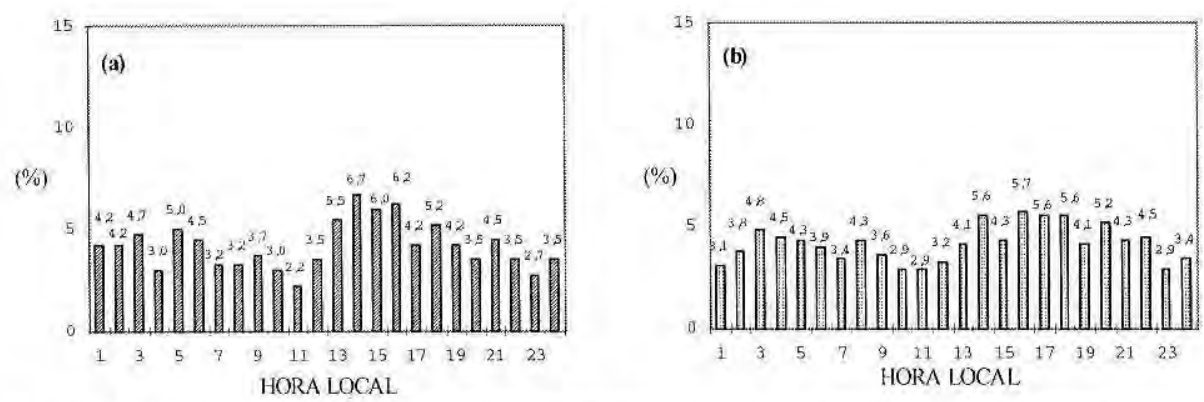

Figura 3. Variabilidade diurna de precipitação maior que $1 \mathrm{~mm} \mathrm{~h}^{-1}$, durante o trimestre chuvoso (jan/fev/ mar) no período de 1992 a 1995. (a) Área de Pastagem. (b) Área de Floresta.

Para uma visualização do período de maior frequência de ocorrência de precipitação superior a $1 \mathrm{~mm} \mathrm{~h}^{-1}$, é utilizada a integração em intervalos de 6 horas (Fig. 4). Na área de pastagem (a) ocorre uma concentração acentuada entre $13-18 \mathrm{hl}$ com $33,5 \%$ dos casos, enquanto apenas $19,1 \%$ estào entre $7-12 \mathrm{hl}$. O período diurno ( $7-18 \mathrm{hl}$ ) detém $52,6 \%$ dos casos, e a fase noturna (19-6 hl) possui $47,4 \%$. Este fato, possivelmente ocorre em função da diminuição da camada turbulenta à noite, inibindo a manutenção e o desenvolvimento da nebulosidade existente. Para a floresta (b) a maior concentração também é verificada à tarde $(30,9 \%)$, entretanto há um quase equlíbrio entre os periodos diurno e noturno. Durante o dia $(7-18 \mathrm{hl})$

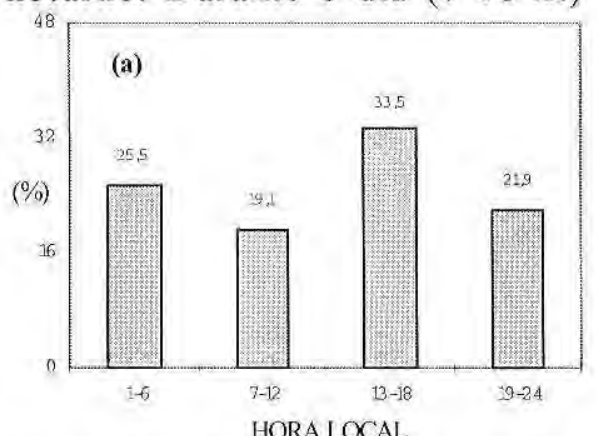

ocorrem $51,2 \%$ dos casos, enquanto à noite (19-6 hl) ocorrem 48,8\%. Esta distribuição regular deve-se à capacidade de atenuação exercida pela floresta com relação a retenção/ liberação de energia no sistema.

As frequências de precipitação foram computadas ano a ano e depois integradas para todo o período. $\mathrm{O}$ número de eventos de precipitação das áreas de pastagem e floresta estão no anexo A. Na pastagem os anos de 1992, 1993 e 1994 mostram um número superior a 100 eventos no trimestre, enquanto o ano de 1995 registra apenas 41 eventos. Isto é explicado pela menor quantidade de dados disponivel na pastagem para aquele ano, somente $71,1 \%$. Entretanto

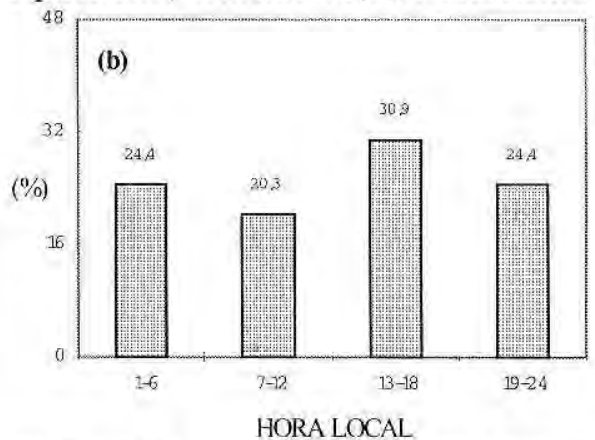

Figura 4. Variabilidade diurna de precipitação maior que $1 \mathrm{~mm} \mathrm{~h}^{-1}$, integrada a cada 6 horas durante 0 trimestre chuvoso (jan/fev/mar) no período de 1992 a 1995. (a) Área de Pastagem. (b) Área de Floresta. 
esse fato não influência os resultados de frequências, pois são valores relativos horários. Nos eventos ocorridos na floresta, para os quatro anos analisados, o total de eventos registrados trimestralmente está acima de 100, e também são superiores aos de pastagem nos mesmos periodos, exceto 0 ano de 1992 que apresenta 132 eventos na floresta contra 142 na pastagem. Isto também se explica pelo menor número de dados disponivel para a floresta naquele ano $(78 \%)$, ao passo que na pastagem a disponibilidade foi integral.

Do total de eventos de precipitação ocorridos na região, $14 \%$ são de precipitações de grande intensidade, ou seja, maiores que $10 \mathrm{~mm} \mathrm{~h}^{-1}$, tanto na floresta como na pastagem.

Após o estudo das ocorrências de chuvas brandas, tornou-se necessária a análise das informações de eventos de maior intensidade. Ferreira da Costa et al. (1997), estudando os mesmos sítios, porém com apenas dois anos de dados, determinaram a frequência relativa de precipitações maiores que $1 \mathrm{~mm} \mathrm{~h}^{-1} \mathrm{e}$ maiores que $3 \mathrm{~mm} \mathrm{~h}^{-1}$. No caso das chuvas superiores a $3 \mathrm{~mm} \mathrm{~h}^{-1}$ encontraram os horários de $14 \mathrm{hl}$ na pastagem $(8,1 \%)$ e $18 \mathrm{hl}$ na floresta $(6,8 \%)$. Estes horários foram próximos aos determinados para as chuvas maiores que $1 \mathrm{~mm} \mathrm{~h}^{-1}, 15 \mathrm{hl}$ e 17 hl respectivamente.

No presente estudo, analisa-se a frequência de ocorrência de precipitações bem mais intensas, de eventos superiores a $10 \mathrm{~mm} \mathrm{~h}^{-1}$ (Fig. 5 ). Na área de pastagem (a) há uma distribuição menos regular que a ocorrida para as precipitações leves. O horário das $18 \mathrm{hl}$ concentra $12,3 \%$ dos eventos, sendo este o maior indice. A menor frequência ocorre em diversos horários, representando menos de 15\% do maior valor registrado. Quando comparadas à frequência de chuvas leves, as precipitações maiores que 10 $\mathrm{mm} \mathrm{h}^{-1}$ sofrem um retardamento, passando das $14 \mathrm{hl}$ para as $18 \mathrm{hl}$, e uma intensificação na frequência de $6,7 \%$ para $12,3 \%$. Com um forte gradiente térmico, a energia envolvida no processo de formação da nebulosidade faz com que algumas nuvens atinjam a maturidade logo no início da tarde, porém, provocam apenas chuvas mais leves. Após liberar parte da energia nestas chuvas, o processo convectivo continua em atividade, fazendo com que nuvens de maior porte alcancem a maturidade somente no final da tarde. Neste caso, o volume precipitado será maior. Na área de floresta (b) a frequência de ocorrência é maior também às $18 \mathrm{hl}(11,5 \%)$. Os menores indices $(1,3 \%)$ ocorrem em vários horários, com ênfase no periodo noturno. A maior concentração de eventos às $18 \mathrm{hl}$ segue o mesmo processo ocorrido na pastagem; plenitude da atividade convectiva no final da tarde com a maturação da nebulosidade e a precipitação.

Os periodos integrados de 6 horas (Fig.6), mostram uma frequência relativa ainda maior na parte da tarde (13-18 hl ), tanto na pastagem (a) com $42,1 \%$, como na floresta (b) com $37,2 \%$. Para a pastagem, a fase diurna $(7-18 \mathrm{hl})$ concentra quase $2 / 3$ dos eventos superiores a $10 \mathrm{~mm} \mathrm{~h}^{-1}$, indicando a influência do aquecimento sofrido pela superfície na intensificação do processo convectivo. $\mathrm{Na}$ floresta, o periodo diurno detém $57,7 \%$ dos casos, havendo 

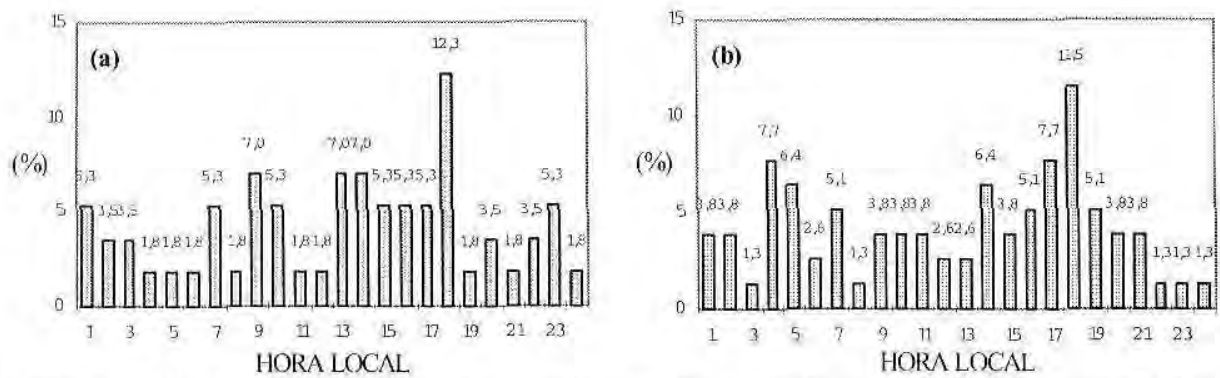

Figura 5. Variabilidade diurna de precipitaçào maior que $10 \mathrm{~mm} \mathrm{~h}^{-1}$, durante o trimestre chuvoso (jan/fev/ mar) no periodo de 1992 a 1995. (a) Área de Pastagem. (b) Área de Floresta.
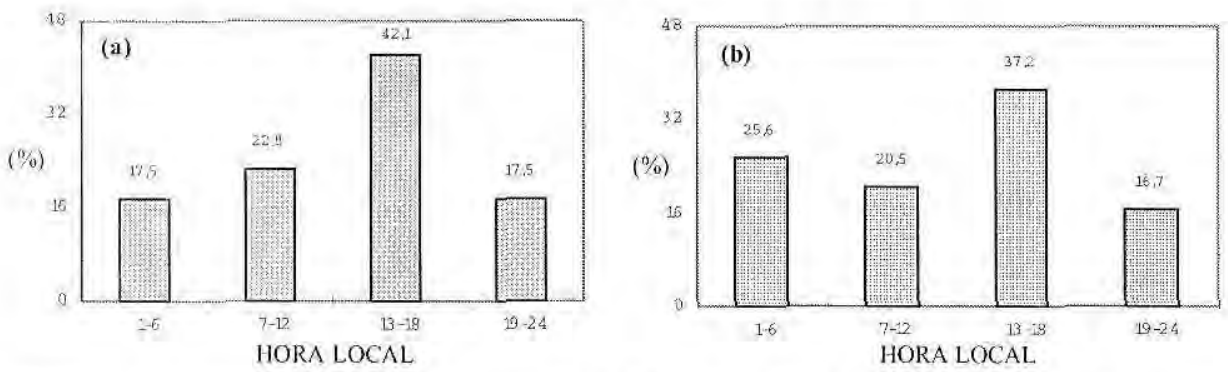

Figura 6. Variabilidade diurna de precipitação maior que $10 \mathrm{~mm} \mathrm{~h}^{-1}$, integrada a cada 6 horas durante 0 trimestre chuvoso (jan/fev/mar) no periodo de 1992 a 1995. (a) Area de Pastagem. (b) Área de Floresta.

uma diferença pouco superior a $15 \% \mathrm{em}$ comparação ao noturno. Isto mostra que a floresta, com sua maior rugosidade produz turbulência e mesmo com a velocidade do vento sofrendo uma reduçâo de intensidade à noite, consegue manter a atividade convectiva durante 0 período entre $19 \mathrm{hl} \mathrm{e} 06 \mathrm{hl}$.

A análise das precipitações maiores que $10 \mathrm{~mm} \mathrm{~h}^{-1}$ mostra que nâo existe a ocorrência de chuvas fortes em todos os horários do dia. Aplicando a razão entre o total de horas da estação chuvosa e o número de eventos de precipitação maiores que $10 \mathrm{~mm} \mathrm{~h}^{-1}$, define-se que há 1 caso de chuva forte, para cada período de aproximadamente 38 horas na pastagem, e 28 horas na floresta. Isto provavelmente devido a necessidade de um periodo maior de tempo para que o processo convectivo atinja sua plenitude e provoque chuva forte. Lloyd \& Marques (1988) analisando dados horários para Manaus - AM entre 1983 e 1985, concluiram que um modelo realístico seria assumir uma tempestade de 2 horas de duração ocorrendo entre 13 e $15 \mathrm{hl} \mathrm{em} 3$ de cada 5 dias, numa taxa de $5,2 \mathrm{~mm} \mathrm{~h}^{-1}$.

Os volumes da precipitação ocorrida na floresta e na pastagem são mostrados na Tabela 4. Como foram selecionados apenas os dias com dados simultâneos, 0 grau de confiabilidade é satisfatório. No ano de 1992, utilizando 71 dias de informações $(78 \%$ ), o volume foi de 621 $\mathrm{mm}$ na floresta e $665 \mathrm{~mm}$ na pastagem. Dos quatro anos pesquisados, este foi 0 único em que a pastagem recebeu um volume maior que a floresta. Em 1993, a floresta registrou $876 \mathrm{~mm}$, e a pastagem $522 \mathrm{~mm}$. Para 1994, o registro foi de 722 $\mathrm{mm}$ na floresta contra $651 \mathrm{~mm}$ na pastagem, e em 1995, $613 \mathrm{~mm}$ e 226 $\mathrm{mm}$, respectivamente. No biênio 92 - 
Tabela 4. Volume precipitado e a diferença registrada entre as áreas de floresta e pastagem durante o trimestre mais chuvoso (jan/fev/mar).

\begin{tabular}{lcccccccc}
\hline & \multicolumn{3}{c}{ Floresta $(\mathrm{mm})$} & \multicolumn{5}{c}{ Pastagem $(\mathrm{mm})$} \\
Ano & 1992 & 1993 & 1994 & 1995 & 1992 & 1993 & 1994 & 1995 \\
\hline Janeiro & 237 & 244 & 209 & 73 & 196 & 194 & 231 & 30,7 \\
Fevereiro & 175 & 302 & 199 & 471 & 133 & 232 & 248 & 98,8 \\
Março & 208 & 331 & 315 & 69,1 & 336 & 95,9 & 172 & 96,1 \\
Trimestre & 621 & 876 & 722 & 613 & 665 & 522 & 651 & 226 \\
\hline Total & & & 1497 & 2219 & 2833 & & & 1187 \\
1837 & 2063 & & & & & & & \\
\hline
\end{tabular}

Diferença de precipitação (volume na floresta maior que na pastagem).

(Período: 1992 e 1993) $311 \mathrm{~mm} \quad(26,2 \%)$

(Periodo: 1992 a 1994) $\quad 382 \mathrm{~mm} \quad(20,8 \%)$

(Periodo: 1992 a 1995) $\quad 770 \mathrm{~mm} \quad(37,3 \%)$

93, há uma diferença de $310 \mathrm{~mm}$ favoráveis à floresta, cerca de 26,2\% (Fig. 7). Quando se amplia o período para 92 94, a diferença aumenta em volume (381 $\mathrm{mm})$ e diminui porcentualmente $(20,8 \%)$. Para o período total (92-95), ocorre um salto na diferença, atingindo $769 \mathrm{~mm}$, que representam $37,3 \%$ a mais na floresta que na pastagem. Aplicando-se uma média entre os diferentes periodos, define-se que na floresta chove aproximadamente $28 \%$ a mais que na pastagem. Para Ghuman \& $\mathrm{Lal}$ (1987) que analisaram áreas de floresta úmida e de clareira na Nigéria nos anos de 1984 e 1985, a chuva registrada dentro da floresta foi respectivamente $12 \%$ e $32 \%$ menor do que a ocorrida na clareira. Porém os autores consideraram a precipitação registrada abaixo do dossel, consequentemente sofrendo o efeito da interceptação pelas folhas e troncos das árvores. A diminuição de precipitação, possivelmente devido ao desmatamento, também ocorreu nos resultados obtidos por Lean et al. (1996), aproximadamente $7 \%$, obtidos através de simulações numéricas do desmatamento da Amazônia. Ubarana (1996), realizando experimentos de perdas por interceptação da precipitação pelo dossel florestal na Reserva Jarú (RJ) e na Reserva Vale do Rio Doce (RV) entre 1992 e 1994 , determinou uma interceptaçãode $11,6 \%$ na RJ e $12,9 \%$ na RV. Quando aplicou o modelo de Rutter aos dados obtidos nas campanhas, Ubarana encontrou $15,6 \%$ e $14,1 \%$ de perda respectivamente.

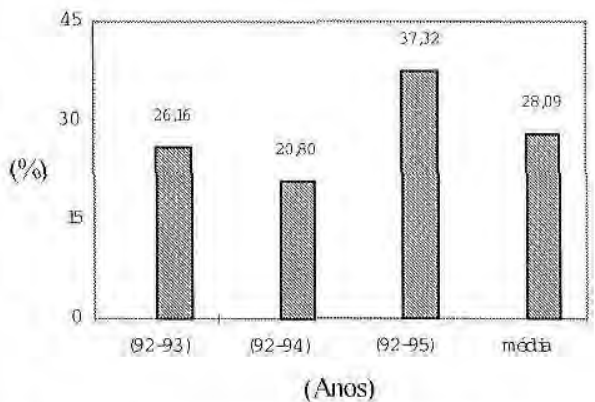

Figura 7. Diferença porcentual do volume de precipitaçào durante o trimestre chuveso (jan/fev/mar) Floresta maior que Pastagem. 


\section{CONCLUSÃo}

Na região sudoeste da Amazônia brasileira, a variabilidade diária de precipitação mostra uma distribuição bastante regular quando se trata de eventos superiores a $1 \mathrm{~mm} \mathrm{~h}^{-1}$, tanto na floresta como na pastagem. Dentro do periodo analisado (Projeto ABRACOS/92-95), a floresta tem a maior concentração $(5,7 \%)$ às $16 \mathrm{hl}$, e a pastagem $(6,7 \%)$ às $14 \mathrm{hl}$. O período da tarde (13-18 hl) detém mais de 30\% dos eventos. A floresta apresenta uma distribuição mais regular que a pastagem. Para as chuvas maiores que $10 \mathrm{~mm} \mathrm{~h}^{-1}$, as ocorrências concentramse claramente no final da tarde, tanto na floresta $(11,5 \%)$, como na pastagem $(12,3 \%)$, isto se dá às $18 \mathrm{hl}$. Na floresta, $57,7 \%$ dos casos de precipitação e na pastagem $64,9 \%$ estão no período de 7 às $18 \mathrm{hl}$. As precipitações de grande intensidade, maiores que $10 \mathrm{~mm} \mathrm{~h}^{-1}$, representam $14 \%$ do total de ocorrências, tanto para a floresta como para a pastagem. Analisando as alterações da quantidade de chuva ocorridas, possivelmente devido as modificações de cobertura vegetal, a precipitação foi em média $28 \%$ maior na floresta do que na pastagem.

\section{AGRADECIMENTOS}

Os autores agradecem a todos aqueles colegas que estiveram envolvidos nas coletas de campo e também ao suporte financeiro do CNPq através das Bolsas RHAE: $381.286-97 / 5$ (R. Ferreira da Costa); 360.527/96-5 (J.R.P. Feitosa) e $360.144 / 97-7$ (S.S. de Souza).

\section{Bibliografia citada}

Culf, A.D.; Fisch, G. ; Hodnett, M.G. 1995. The albedo of Amazonia forest and ranchland. Journai of Climate, 8 (6): 1544-1554.

Ferreira da Costa, R.; Feitosa, J.R.P; Fisch, G.; Ramos, A.M. 1997. Variabilidade diuma da precipitação em áreas de floresta e pastagem em Rondônia - Época chuvosa. In ANON. (eds). Anais do X Congresso Brasileiro de Agrometeorologia. Sociedade Brasileira de Agrometeorologia, Piracicaba, SP, p. 274-276.

Figueroa, S.N,; Nobre, C.A. 1990. Precipitation distribution over Central and western Tropical South America. Climanálise, 5 (6): 36-45.

Fisch, G.; Marengo, J,; Nobre, C.A 1996. Clima da Amazônia. Climanálise Especial, Ediçăo Comemorativa de 10 anos,.p. 24-41.

Fisch, G.; Lean, J.; Wright, J.R; Nobre, C.A. 1997. Simulaçōes climáticas do efeito do desmatamento na região amazônica: Estudo de um caso em Rondônia. Revista Brasileira de Meteorologia, 12(1): 33-48.

Gash, J.H.C.; Nobre, C.A.; Roberts, J.M; Victoria, R.L. 1996. An overview of Abracos. In J.H.C. Gash; C.A. Nobre; J.M. Roberts, and R.L. Victoria, (eds.) Amazonian Deforestation And Climate, John Wiley and Sons, Chichester - UK, p. 1-14.

Ghuman, B.S.; Lal, R. 1987. Effects of partial clearing on microclimate in a humid tropical forest. Agricultural and Forest Meteorology, 40(1): 17-29.

Grecco, S. Swap, R; Garstang, M; Ulanski, S.; Shipham, M.; Harris, R.C.; Talbot, R.; Andreae, M.O.; Artaxo, P. 1990. Rainfall and surface kinematic conditions over central Amazonia during Able 2b. Journal of Geophysical Research, 95(D10): 17001-17014.

Harris, R.C. et al. 1988. The Amazon Boundary Layer Experiment - Able 2a - Dry season 1985, Joumal of Geoplysical Research, 93: 1477-1486.

Harriss, R.C.; Garstang, M; Wofsy, S.C.; Beck, S.M.; Bendura, R.J.; Coelho, J.R.B.; Drewry, J.W,; Hoell JR., J.M; Matson, P.A.; Meneal, R.J.; Molion, L.C.B.; Navarro, R.L.; Rabine, V.; Snell, R.L. 1990. The Amazon Boundary Layer Ex- 
periment - Wet season 1987, Journal of Geophysical Research, 95(D10): 16721-16736.

Horel, J.H.; Hahmann, A.N.; Geisler, J.E. 1989, An investigation of the annual cycle of convective activity over the tropical Americas, Jounnal of Climate, 2(11): 1388-1403.

Instituto Brasileiro de Geografia e Estatistica - IBGE 1996. Censo Populacional 1996.

Lean, J.H.; Button, C.B.; Nobre, C.A.; Rowntree, P.R. 1996. The simulated impact of Amazonian deforestation on climate using measured Abracos vegetation characteristics. In J.H.C. Gash; C.A. Nobre; J.M. Roberts, and R.L. Victoria, (eds.) Amazonian Deforestation And Climate, John Wiley and Sons, Chichester UK, p. 549-576.

Lloyd, C.R;; Marques, A.de O. 1988. Spatial variability of throghfall measurements in Amazonia rainforest. Agricultural and Forest Meteorology, 42: 63-73.

McWilliam, A.L.C.; Cabral, O.M.R.; Gomes, B.M.; Esteves, J.L.; Roberts, J.M. 1996. Forest and pasture leaf-gas exchange in South-West Amazonia. In J.H.C. Gash; C.A. Nobre; J.M. Roberts, and R.L. Victoria, (eds.) Amazonian Deforestation And Climate, John Wiley and Sons, Chichester - UK, p. 265-285.

Nobre, C.A.; Sellers, P.J.; Shukla, J. 1991. Amazonian deforestation and regional change. Journal of Climate, 4: 957-988.

Paiva, E.M.C.D. de 1996. Regime de precipitação na Amazônia e sua relação com o desmatamento e temperatura da superficie do mar. Tese de Doutoramento em Engenharia de Recursos Hidricos e Saneamento Ambiental Universidade Federal do Rio Grande do Sul - Instituto de Pesquisas Hidrálicas. Porto Alegre - RS. 297 p.
Peagle, J. 1987. Interactions between convective and large-scale motions over Amazonia. In R.E. Dickinson (eds.) The Geophysiology of Amazonia: Vegetation and Climate Interactions, - John Wiley and Sons. New York USA, p. 347-387.

Salati, E., Marques, J.; Molion, L.C.B. 1978. Origem e distribuição das chuvas na Amazônia. Interciência, 3: 200-206.

Scerne, R.M.C.; Santos,A.O. da S.; Santos, M.M.; Antonio Neto, F. 1996 - Aspectos agroclimáticos da região de Ouro Prêto D'Oeste - RO, CEPLAC/SUPOR, Boletim Técnico 13, Belém, PA, 40 p.

Shuttleworth, W.J.; Gash, J.H.C.; Lloyd, C.R.; Moore, C.J.; Roberts, J.M.; Marques, A. de O.; Fisch, G.; Silva, V. de P.; Ribeiro, M.N.G., Molion, L.C.B.; de Abreu Sá, L.D.; Nobre, C.A.;Cabral, O.M.R.; Patel, S.R.; Moraes, J.C. 1984. Eddy correlation measurements of energy partition for Amazonian forest, Quarlerly Journal of Royal Meteorological Society, 110 (466): 1143-1162.

Shuttleworth, W.J.; Gash, J.H.C.; Roberts, J.M.; Nobre, C.A.; Molion, L.C.B.; Ribeiro, M.N.G, 1991. Post-deforestation Amazonian climate: Anglo-Brazilian research to improve prediction. Journal of Hydrology, 129(1): 71-86.

Spiegel, M. R. 1972. Estatistica McGraw-Hill do Brasil, São Paulo, 580 p.

Ubarana, V.N. 1996. Observation and modelling of rainfall interception loss in two experimental sites in Amazonian forest. In J.H.C. Gash; C.A. Nobre; J.M. Roberts, and R.L Victoria, (eds.) Amazonian Deforestation And Climate, John Wiley and Sons. Chichester - UK, p. 151-162. 


\section{6-ANEXO: A}

Número de eventos de precipitação maiores que $1 \mathrm{~mm} \mathrm{~h}^{-1}$ na Floresta e Pastagem, ocorridos no periodo de janeiro, fevereiro e março dos anos de 1992 a 1995.

\begin{tabular}{ccccccccccc}
\hline Hora & \multicolumn{7}{c}{ FLORESTA } & & & \multicolumn{7}{c}{ PASTAGEM } \\
local & 1992 & 1993 & 1994 & 1995 & $92-95$ & 1992 & 1993 & 1994 & 1995 & $92-95$ \\
\hline 1 & 5 & 6 & 1 & 5 & 17 & 7 & 5 & 5 & 0 & 17 \\
2 & 6 & 5 & 3 & 7 & 21 & 6 & 6 & 5 & 0 & 17 \\
3 & 10 & 6 & 5 & 6 & 27 & 7 & 4 & 6 & 2 & 19 \\
4 & 5 & 9 & 6 & 5 & 25 & 1 & 4 & 6 & 1 & 12 \\
5 & 4 & 8 & 8 & 4 & 24 & 3 & 6 & 8 & 3 & 20 \\
6 & 4 & 7 & 7 & 4 & 22 & 6 & 5 & 5 & 2 & 18 \\
\hline 7 & 1 & 7 & 6 & 5 & 19 & 3 & 6 & 3 & 1 & 13 \\
8 & 1 & 11 & 6 & 6 & 24 & 2 & 4 & 4 & 3 & 13 \\
9 & 3 & 7 & 5 & 5 & 20 & 6 & 5 & 2 & 2 & 15 \\
10 & 3 & 5 & 5 & 3 & 16 & 5 & 3 & 3 & 1 & 12 \\
11 & 1 & 8 & 3 & 4 & 16 & 3 & 3 & 3 & 0 & 9 \\
12 & 3 & 6 & 7 & 2 & 18 & 8 & 5 & 1 & 0 & 14 \\
\hline 13 & 3 & 9 & 5 & 6 & 23 & 8 & 7 & 6 & 1 & 22 \\
14 & 6 & 11 & 8 & 6 & 31 & 11 & 6 & 6 & 4 & 27 \\
15 & 6 & 8 & 6 & 4 & 24 & 9 & 10 & 3 & 2 & 24 \\
16 & 9 & 9 & 8 & 6 & 32 & 9 & 6 & 10 & 0 & 25 \\
17 & 10 & 9 & 5 & 7 & 31 & 9 & 2 & 3 & 3 & 17 \\
18 & 9 & 9 & 5 & 8 & 31 & 9 & 3 & 5 & 4 & 21 \\
\hline 19 & 10 & 4 & 2 & 7 & 23 & 5 & 3 & 4 & 5 & 17 \\
20 & 11 & 6 & 4 & 8 & 29 & 5 & 6 & 3 & 0 & 14 \\
21 & 8 & 6 & 3 & 7 & 24 & 5 & 7 & 3 & 3 & 18 \\
22 & 7 & 6 & 3 & 9 & 25 & 5 & 3 & 3 & 3 & 14 \\
23 & 2 & 5 & 4 & 5 & 16 & 4 & 4 & 3 & 0 & 11 \\
24 & 5 & 7 & 2 & 5 & 19 & 6 & 3 & 4 & 1 & 14 \\
\hline Total & 132 & 174 & 117 & 134 & 557 & 142 & 116 & 104 & 41 & 403 \\
\hline & & & & & & & & & & \\
\hline
\end{tabular}

Número de eventos de precipitação maiores que $10 \mathrm{~mm} \mathrm{~h}^{-1}$ na Floresta e Pastagem, ocorridos no periodo de janeiro, fevereiro e março dos anos de 1992 a 1995.

\begin{tabular}{lcccccccccc}
\hline Hora & \multicolumn{1}{c}{ FLORESTA } & & \multicolumn{7}{c}{ PASTAGEM } \\
local & 1992 & 1993 & 1994 & 1995 & $92-95$ & 1992 & 1993 & 1994 & 1995 & $92-95$ \\
\hline 1 & 1 & 0 & 0 & 2 & 3 & 0 & 0 & 3 & 0 & 3 \\
2 & 1 & 0 & 1 & 1 & 3 & 1 & 0 & 1 & 0 & 2 \\
3 & 0 & 0 & 1 & 0 & 1 & 1 & 0 & 0 & 1 & 2 \\
4 & 0 & 4 & 2 & 0 & 6 & 0 & 0 & 1 & 0 & 1 \\
5 & 1 & 1 & 2 & 1 & 5 & 1 & 0 & 0 & 0 & 1 \\
6 & 1 & 0 & 0 & 1 & 2 & 1 & 0 & 0 & 0 & 1 \\
\hline 7 & 1 & 0 & 2 & 1 & 4 & 2 & 1 & 0 & 0 & 3 \\
8 & 0 & 0 & 1 & 0 & 1 & 0 & 1 & 0 & 0 & 1 \\
9 & 0 & 0 & 1 & 2 & 3 & 3 & 0 & 0 & 1 & 4 \\
10 & 1 & 0 & 0 & 2 & 3 & 3 & 0 & 0 & 0 & 3 \\
11 & 0 & 1 & 1 & 1 & 3 & 0 & 0 & 1 & 0 & 1 \\
12 & 0 & 0 & 1 & 1 & 2 & 0 & 0 & 1 & 0 & 1 \\
\hline 13 & 1 & 1 & 0 & 0 & 2 & 1 & 0 & 3 & 0 & 4 \\
14 & 4 & 0 & 1 & 0 & 5 & 2 & 1 & 0 & 1 & 4 \\
15 & 1 & 2 & 0 & 0 & 3 & 2 & 0 & 1 & 0 & 3 \\
16 & 0 & 2 & 1 & 1 & 4 & 0 & 2 & 1 & 0 & 3 \\
17 & 4 & 0 & 1 & 1 & 6 & 2 & 1 & 0 & 0 & 3 \\
18 & 3 & 2 & 1 & 3 & 9 & 3 & 1 & 1 & 2 & 7 \\
\hline 19 & 2 & 0 & 0 & 2 & 4 & 1 & 0 & 0 & 0 & 1 \\
20 & 1 & 1 & 0 & 1 & 3 & 0 & 1 & 1 & 0 & 2 \\
21 & 1 & 0 & 1 & 1 & 3 & 0 & 1 & 0 & 0 & 1 \\
22 & 0 & 0 & 0 & 1 & 1 & 1 & 0 & 1 & 0 & 2 \\
23 & 1 & 0 & 0 & 0 & 1 & 2 & 0 & 1 & 0 & 3 \\
24 & 1 & 0 & 0 & 0 & 1 & 0 & 0 & 1 & 0 & 1 \\
\hline Total & 25 & 14 & 17 & 22 & 78 & 26 & 9 & 17 & 5 & 57 \\
\hline & & & & & & & & & &
\end{tabular}

